\title{
Endobronchial valve for treatment of persistent air leak complicating spontaneous pneumothorax
}

\author{
WC Yu *, Ellen LM Yu, HC Kwok, HL She, KK Kwong, YH Chan, YL Tsang, YC Yeung
}

\section{A B S T R A C T}

Introduction: Endobronchial one-way valves have been proposed as treatment for persistent air leak complicating spontaneous pneumothorax in which surgical intervention is not feasible. However, published data on efficacy, safety, and factors associated with success are scanty.

Methods: This is a retrospective study of 37 patients at a general hospital from 2008 to 2016 . The impact of endobronchial valve implantation on the time to air-leak cessation after bronchoscopy was evaluated.

Results: The median patient age was 71 years. The majority of patients were males $(92 \%)$, were eversmokers (83\%), had at least one co-morbidity (97\%), and had secondary spontaneous pneumothorax (89\%). Nineteen patients (51\%) had a mean of 2.6 endobronchial valves implanted (range, 1-6). The air leak ceased within 72 hours for only eight patients (22\% of the complete cohort), with immediate airleak cessation after completion of endobronchial valve implantation. All six successful cases that had computed tomographic data of the thorax were shown to have bilateral intact interlobar fissures. The median (interquartile range) Charlson co-morbidity index was $1(0.25-1)$ and 2 (1-3) for the success group and failure group, respectively $(\mathrm{P}=0.029)$. All patients
This article was published on $4 \mathrm{Apr}$ 2018 at www.hkmj.org. whereas three patients in the endobronchial valve group died within 30 days of endobronchial valve implantation.

Conclusion: Only a small proportion of cases of endobronchial valve implantation for air leak complicating pneumothorax had unequivocal success. Intact bilateral interlobar fissures appear to be a necessary, though not sufficient, condition for success. Patients with fewer medical co-morbidities and immediate air-leak cessation after endobronchial valve implantation have a higher likelihood of success.

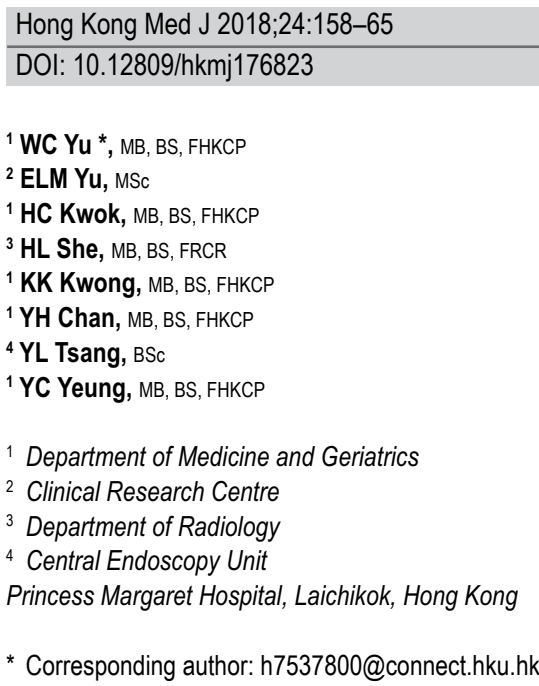

${ }^{1} \mathrm{WC} Y \mathrm{Yu}^{*}, \mathrm{MB}, \mathrm{BS}, \mathrm{FHKCP}$

ELM Yu, MSC

${ }^{1}$ HC Kwok, MB, BS, FHKCP

${ }^{3} \mathrm{HL}$ She, MB, BS, FRCR

${ }^{1}$ KK Kwong, MB, BS, FHKCP

${ }^{1}$ YH Chan, MB, BS, FHKCP

${ }^{4}$ YL Tsang, BSc

${ }^{1}$ YC Yeung, MB, BS, FHKCP

1 Department of Medicine and Geriatrics

2 Clinical Research Centre

${ }^{3}$ Department of Radiology

${ }^{4}$ Central Endoscopy Unit

Princess Margaret Hospital, Laichikok, Hong Kong

* Corresponding author: h7537800@connect.hku.hk

New knowledge added by this study

- Only a small proportion of cases (22\%) of persistent air leak complicating spontaneous pneumothorax can be successfully treated by endobronchial valve (EBV).

- Cases in which the air leak does not cease immediately after completion of EBV implantation are likely to fail.

- Patients with any non-intact interlobar fissures are likely to experience treatment failure.

Implications for clinical practice or policy

- EBV treatment may be attempted in patients with persistent air leak complicating spontaneous pneumothorax who are not candidates for surgery, have intact interlobar fissures, and do not have severe medical comorbidities.

- Plain computed tomography of the thorax should be performed to routinely assess patients who are candidates for EBV treatment.

- Cases of completed EBV implantation that still have an air leak may have the EBVs removed.

\section{Introduction}

Persistent air leak is a common complication of spontaneous pneumothorax being treated by chest tube drainage. In one report, the median time for spontaneous cessation of air leak was 7 days for primary spontaneous pneumothorax and 11 days for secondary spontaneous pneumothorax. ${ }^{1}$ In another report, $75 \%$ and $100 \%$ of cases of primary spontaneous pneumothorax resolved by 7 days and 14 days, respectively, whereas the corresponding proportions for secondary spontaneous pneumothorax were $61 \%$ and $79 \%$, respectively. ${ }^{2}$ It is generally recommended that surgical intervention be considered when an air leak continues for 7 to 14 days after chest tube insertion. Unfortunately, some patients are poor candidates for surgery, and some 
patients may refuse surgery. Prolonged chest tube in situ, however, is undesirable because of an increased risk of complications, prolonged immobilisation and its consequences, and increased duration of hospital stay. Alternative means to shorten the duration of air leakage are thus needed.

Endobronchial one-way valves (EBVs) have been used to treat persistent air leak complicating pneumothorax. The rationale is that air leakage will stop if air is prevented from entering the airway leading to the leak site. Preliminary case reports showed encouraging results. ${ }^{3-14}$ Larger case series showed similarly favourable results. ${ }^{15-23}$ However, most of these reports include a mix of post-surgical pneumothoraces, spontaneous pneumothoraces, and other aetiologies. Moreover, there is scanty information on overall efficacy, short-term safety, and factors related to favourable clinical outcomes.

The Princess Margaret Hospital, an acute-care general hospital in Hong Kong, has been using EBV for persistent air leak complicating pneumothorax on compassionate grounds since 2008, and its preliminary experience on three apparently successful cases was reported in 2009. ${ }^{11}$ However, it was subsequently found that in many cases, the leak site could not be identified, so EBV could not be deployed. In some other cases, despite leak site identification and EBV deployment, the air leak may not resolve completely, or it may recur after a few hours. We therefore hypothesise that EBV treatment has a low success rate in real-life situations. To test this hypothesis, we retrospectively compared the clinical course of patients with and without EBV use for persistent air leak complicating spontaneous pneumothorax during an 8-year period at a single centre.

\section{Methods}

\section{Patients}

This retrospective chart review was based on patients who were managed at the Princess Margaret Hospital from May 2008 to April 2016. Eligible patients were those with spontaneous pneumothorax who were undergoing chest tube drainage and who had had an air leak lasting more than 1 week. All showed bubbling in the drainage bottle during both expiration and inspiration, with water suction at $-20 \mathrm{~cm}$. Patients either refused surgery or were considered by the thoracic surgeon to be unsuitable for surgical intervention owing to advanced age, poor lung function, major medical co-morbidities, or a combination of these.

\section{Intervention}

Bronchoscopy with the intention of EBV implantation to stop the air leak was suggested to eligible patients. Some were reluctant at first but consented after

\section{支氣管內瓣膜治療持續氣漏併發自發性氣胸 余衛祖、余洛汶、郭孝聰、余凱琳、鄺建强、陳宇康、 曾月玲、楊耀昌}

引言：支氣管內單向瓣膜被認為是當手術不可行時, 治療持續氣漏併 發自發性氣胸的療法。然而, 有關這種療法的有效性、安全性和成功 因素的數據卻廖廖可數。

方法：這項回顧性研究納入 2008年至2016年期間在一所全科醫院的 37 名患者, 評估他們在支氣管鏡檢查後支氣管內瓣膜置入對氣漏停止 時間的影響。

結果：患者的年齡中位數為 71 歲，大部份為男性（92\%）、曾有吸 煙習慣（83\%）、至少有一項併發症（97\%），以及繼發性自發性 氣胸（ $89 \%) 。 19$ 名患者（ $51 \%$ ) 平均植入 2.6 個支氣管內瓣膜（範 圍：1-6個）。只有8名患者 $(22 \%)$ 在 72 小時內停止氣漏, 並且在支 氣管內瓣膜置入後立即停止氣漏。6 個成功病例的胸腔電腦斷層掃描 數據均顯示雙側完整葉間裂隙。治療成功組別和失敗組別的Charlson 併發症指數的中位數（四分位數間距）分別為1（0.25-1）和2（1-3） $〔 P=0.029 〕$ 。所有在非支氣管內瓣膜組別的患者均存活, 而支氣管 內瓣膜組別中有三名患者在支氣管內瓣膜置入後 30 天內死亡。

結論：只有一小部份病例取得明確成功。完整的雙側葉間裂縫可能是 必要的, 但並不足以影響治療成功的條件。支氣管內瓣膜置入術對術 後併發症較少且能立即停止氣漏的患者的治療成功率較高。這種治療 形式的安全性和有效性須在隨機對照試驗中作進一步評估。

further days of air leakage. Procedures for identifying the leak site and deploying EBV were as described previously. ${ }^{11}$ Briefly, an endobronchial inflatable balloon was used to occlude lobar or segmental bronchi sequentially. If bubbling from the chest drainage bottle stopped, or was greatly reduced, then the lobe or segment was selected for endobronchial valve implantation. The Zephyr EBV (Emphasys Inc, now Pulmonx Inc, Redwood City [CA], United States) was used throughout. Patients were observed closely for continued air leak after bronchoscopy. Chest tubes were removed as soon as possible after air-leak cessation, typically within 1 or 2 days, as is usual clinical practice.

\section{Data collection and outcome measures}

Data on demographic and disease characteristics, details of bronchoscopy, and survival after bronchoscopy were recorded. Spirometry data were analysed if available within 1 year of bronchoscopy. Spirometry was performed according to the American Thoracic Society / European Respiratory Society criteria ${ }^{24}$ and using reference values for Hong Kong adults. ${ }^{25}$ No spirometry was performed during the period of chest tube drainage or with EBV in situ. Computed tomography images, if available, were viewed in axial, sagittal, and coronal planes by a single radiologist who was blinded to other study data. The integrity of the fissures was defined as more than $90 \%$ completeness on at least one axis. ${ }^{26}$ 
Outcome measures included whether EBV was implanted, time to air-leak cessation, and 30-day allcause mortality after bronchoscopy.

\section{Definition of therapeutic success}

Therapeutic success was defined as cessation of the air leak within 72 hours of EBV implantation. Cases with EBV implanted but with the air leak lasting more than 72 hours afterwards, cessation of air leak within 72 hours of bronchoscopy owing to other interventions (such as surgery), cases without EBV implantation, and cases of chest tube removal while the air leak persisted (such as following unintended displacement) were considered cases of failure.

\section{Statistical analysis}

The Mann-Whitney $U$ test and Fisher's exact test were used to examine differences between groups. The Kaplan-Meier log-rank test and Gehan-BreslowWilcoxon test were used to analyse time to air-leak cessation after first bronchoscopy among patients with and without EBV implantation. The association between EBV implantation and air-leak cessation was assessed in a multivariable Cox proportional hazards regression model that was adjusted for 'days on chest tube before first bronchoscopy' and factors with $\mathrm{P}<0.2$ in univariable regression analyses. The accuracy, sensitivity, specificity, and positive and negative predictive values of using the presence of an intact interlobar fissure as an indicator of a successful outcome were calculated. Statistical analyses were performed using SPSS 22.0 for Windows (IBM Corp., Armonk [NY], United States) and OpenEpi: Open Source Epidemiologic Statistics for Public Health, version 3.01 (http://www.openepi.com). Statistical significance was set at $\mathrm{P}<0.05$.

This study was approved by the Research Ethics Committee of the Kowloon West Cluster of the Hong Kong Hospital Authority, with the requirement for patient consent waived. This report conforms to the STROBE 2008 guidelines. ${ }^{27}$

\section{Results}

\section{Baseline characteristics}

During the study period, 38 patients underwent bronchoscopy for persistent air leak complicating spontaneous pneumothorax at our institution. One patient was excluded because the air leak was subsequently found to result from the chest tube having been inserted into an airway. Of the remaining 37 patients, 35 were assessed by the surgeon and considered unfit for surgery, and two patients with primary spontaneous pneumothorax refused surgery. The median patient age was 71 years and most $(34 ; 92 \%)$ were males. The majority $(83 \%)$ were ever-smokers. All but one (97\%) had at least one co-morbidity and the median Charlson co-morbidity index was 1. Fifteen patients (41\%) had a left pneumothorax. Thirty-three (89\%) had secondary spontaneous pneumothorax, of which 23 had chronic obstructive pulmonary disease with or without other lung diseases. Of the 22 secondary spontaneous pneumothorax cases with spirometric data, the median forced expiratory volume in 1 second $\left(\mathrm{FEV}_{1}\right)$ was $0.94 \mathrm{~L}$; median percentage of predicted $\mathrm{FEV}_{1}$ was $43.5 \%$; and median $\mathrm{FEV}_{1}$ to forced vital capacity ratio was 0.45 . Eleven patients $(30 \%)$ had at least one attempt at talc pleurodesis before bronchoscopy. The median number of days off chest tube use before bronchoscopy was 25 (Table 1).

TABLE I. Baseline characteristics of patients with and without endobronchial valve implantation at first bronchosopy*

\begin{tabular}{|c|c|c|c|c|}
\hline Variable & EBV implanted $(n=19)$ & EBV not implanted $(n=18)$ & $\mathrm{P}$ valuet & All patients $(n=37)$ \\
\hline Age, y & $72.0(65.00-79.00)$ & $70.5(65.25-75.00)$ & 0.641 & $71.0(65.0-78.5)$ \\
\hline Males, No. (\%) & $16(84.2)$ & $18(100)$ & 0.230 & 34 (91.9) \\
\hline Ever-smokers, No. (\%)‡ & $9(75.0)$ & $10(90.9)$ & 0.590 & 19 (82.6) \\
\hline Charlson co-morbidity index & $1(1-4)$ & $1.5(1-2.25)$ & $>0.999$ & $1(1-3)$ \\
\hline Left pneumothorax, No. (\%) & $7(36.8)$ & $8(44.4)$ & 0.743 & $15(40.5)$ \\
\hline Secondary pneumothorax, No. (\%) & $17(89.5)$ & $16(88.9)$ & $>0.999$ & $33(89.2)$ \\
\hline $\mathrm{FEV}_{1}, \mathrm{~L} \S$ & $0.72(0.65-1.00)$ & $1.13(0.88-1.59)$ & 0.043 & $0.94(0.70-1.28)$ \\
\hline $\mathrm{FEV}_{1} \%$ predicted§ & $37.0(27.00-49.50)$ & $46.0(32.75-54.75)$ & 0.228 & $43.5(29.75-54.25)$ \\
\hline $\mathrm{FEV}_{1} / \mathrm{FVC} \S$ & $0.41(0.34-0.67)$ & $0.47(0.35-0.63)$ & 0.539 & $0.45(0.34-0.65)$ \\
\hline Any medical pleurodesis before bronchoscopy, №. (\%) & $6(31.6)$ & $5(27.8)$ & $>0.999$ & $11(29.7)$ \\
\hline Days on chest tube before first bronchoscopy & $29(22.00-48.00)$ & $20(15.75-28.25)$ & 0.042 & $25(16-37)$ \\
\hline
\end{tabular}

Abbreviations: COPD = chronic obstructive pulmonary disease; EBV = endobronchial valve; FEV $=$ forced expiratory volume in I second; FVC = forced vital capacity

* Values are expressed as median (interquartile range), except where noted

+ Fisher's exact test or Mann-Whitney $U$ test, as appropriate

‡ No. of cases=23: I2 EBV implanted; I I EBV not implanted

$\S$ For patients with secondary pneumothorax only (No. of cases = 22: 10 EBV implanted; I 2 EBV not implanted) 


\section{Endobronchial one-way valve implantation and time to air-leak cessation}

Nineteen patients (51\%) had a mean of 2.6 EBVs implanted (range, 1-6). The sites of EBV implantation were as follows: 11 in the right upper lobe, one in the right middle lobe, none in the right lower lobe, five in the left upper lobe, and two in the left lower lobe. Of the 18 patients without an EBV implanted, the target site for EBV implantation could not be identified in 17. In the remaining patient, despite identification of the air leak in the left upper lobe, EBV implantation was followed by severe oxygen desaturation and had to be abandoned.

There were eight successful cases among patients with EBVs implanted. Among these, seven patients had immediate and lasting cessation of the air leak, and the chest tube was removed within 2 days. One patient had immediate air-leak cessation but there was recurrence after 2 hours. The air leak subsided completely within 72 hours, and the chest tube was removed on day 4. Among the 11 cases of failure after EBV implantation, the air leak stopped immediately in three cases but recurred soon after and persisted beyond 72 hours. In the other eight cases, the air leak was reduced temporarily but was present beyond 72 hours. In the group without an implanted EBV, the earliest time for airleak cessation was day 5 , and the chest tube was removed on day 8. In a Kaplan-Meier comparison of the EBV and no-EBV groups in the number of days from first bronchoscopy to air-leak cessation, the EBV group did better in the first 30 days, but the no-EBV group caught up by day 45 . There was a statistically significant difference between the two groups according to the Gehan-Breslow-Wilcoxon test $(\mathrm{P}=0.027)$, but not the log-rank test $(\mathrm{P}=0.138)$ [Fig Part a]. When the same comparison was done with the eight successful cases removed from the EBV group, the two curves overlapped throughout and there was no statistically significant difference between the two groups $(\mathrm{P}=0.881$ by GehanBreslow-Wilcoxon test and $\mathrm{P}=0.976$ by log-rank test) [Fig Part b].

In a comparison of demographic and clinical characteristics between the EBV group and the no-EBV group, the former had a significantly poorer $\mathrm{FEV}_{1}$, but not percentage of predicted $\mathrm{FEV}_{1}$. This group also had the chest tube in place for a significantly longer duration before bronchoscopy (Table 1).

\section{Factors associated with a successful outcome}

We further examined factors related to airleak cessation after first bronchoscopy by Cox proportional hazards regression analysis. The implantation of an EBV was significantly associated with air-leak cessation (adjusted hazard ratio $=2.39$, 95\% $\mathrm{CI}=1.13-5.05 ; \mathrm{P}=0.023)$, whereas the Charlson

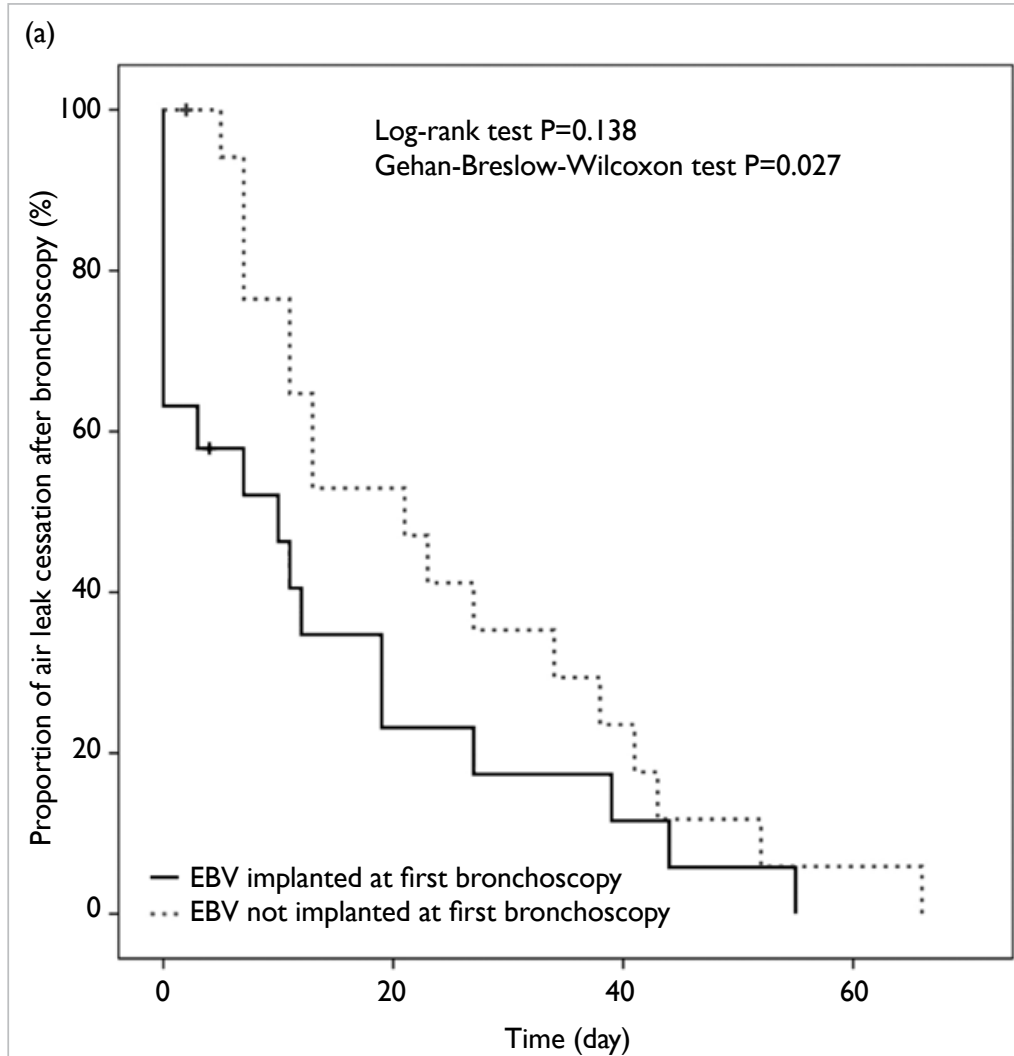

(b)

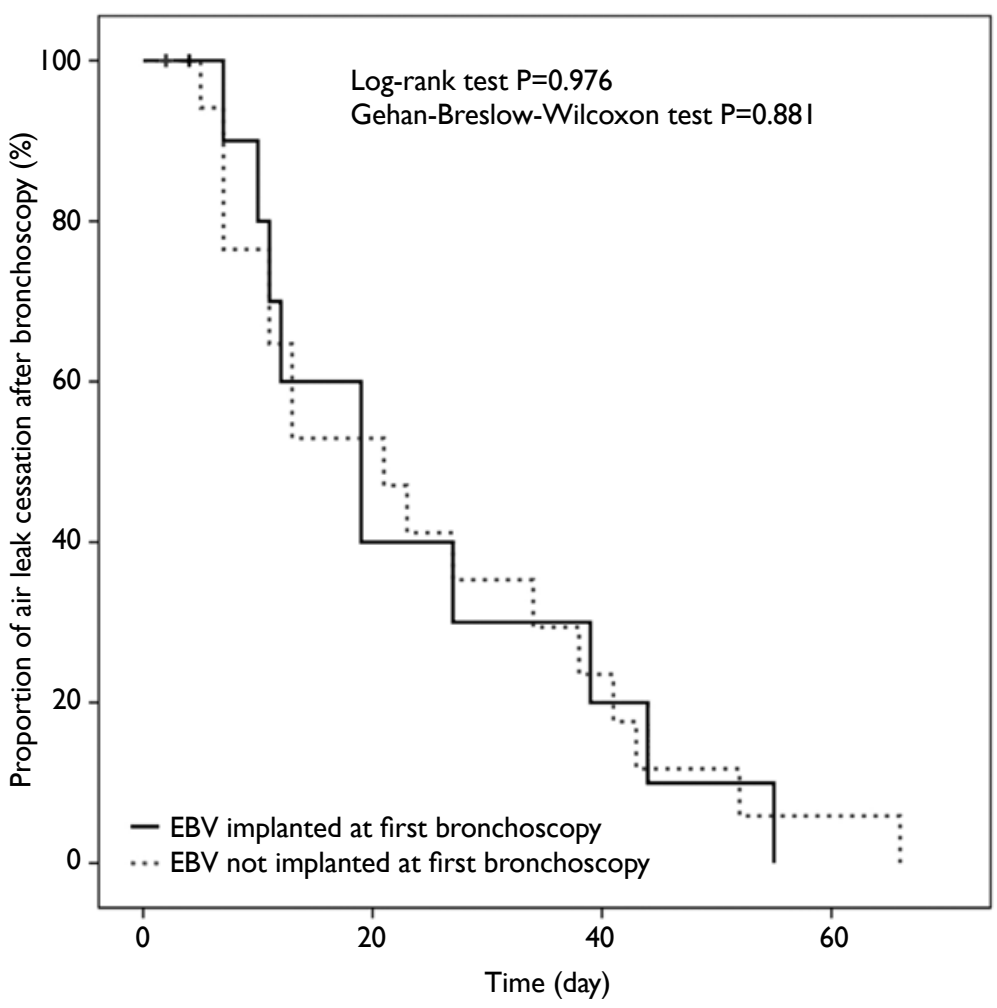

FIG. Kaplan-Meier curves of air-leak cessation after first bronchoscopy in patients with and without an implanted endobronchial valve (EBV): (a) complete cohort; (b) all eight successful cases removed from the EBV implanted group

+ indicates two censored cases: one patient in the EBV implanted group refused chest-tube reinsertion after it slipped out and one in the EBV not-implanted group refused surgical intervention 
co-morbidity index was significantly associated with delayed air-leak cessation (adjusted hazard ratio $=0.78,95 \% \mathrm{CI}=0.63-0.97 ; \mathrm{P}=0.026)$. The number of days of chest tube use before first bronchoscopy was not associated with air-leak cessation (Table 2).

When comparing the eight successful cases with the 11 failed cases among those with implanted EBVs, we found no difference in any of the demographic or disease variables between the two groups, apart from the Charlson co-morbidity index, which was significantly lower for the success group (Table 3). Additionally, all eight patients (100\%) in the success group had air-leak cessation immediately after EBV implantation, versus only three of 11 (27\%) in the failure group $(\mathrm{P}=0.003)$. When we compared the eight successful cases with all 29 failed cases, again the median (interquartile range) Charlson co-morbidity index was significantly lower for the success group: $1(0.25-1)$ vs $2(1-3)[\mathrm{P}=0.029]$. This group also had significantly poorer $\mathrm{FEV}_{1}$, but not in percentage of predicted $\mathrm{FEV}_{1}$, and showed a trend towards more severe airflow obstruction, although this did not reach statistical significance (Table 3).

Twenty-three patients had thoracic computed tomography performed to examine the integrity of interlobar fissures. For the 13 patients with all fissures intact, six had an EBV implanted and were classed as successful cases, four had EBV implanted but were classed as failed cases, and three did not have an EBV implanted. There were five patients each in the group with any non-intact ipsilateral fissure and in the group with any non-intact contralateral fissure. Both groups had two patients with an implanted EBV and three without, and all experienced treatment failure.

When using the presence of all intact fissure(s)

TABLE 2. Cox proportional hazards regression results for air-leak cessation after first bronchoscopy

\begin{tabular}{|c|c|c|c|c|}
\hline \multirow[t]{2}{*}{ Variable } & \multicolumn{2}{|c|}{ Univariable } & \multicolumn{2}{|c|}{ Multivariable } \\
\hline & $\mathrm{HR}_{\text {unadj }}(95 \% \mathrm{Cl})$ & $P$ value & $\mathrm{HR}_{\mathrm{adj}}(95 \% \mathrm{Cl})^{*}$ & $P$ value \\
\hline EBV implantation at first bronchoscopy & $1.63(0.83-3.22)$ & 0.157 & $2.39(1.13-5.05)$ & 0.023 \\
\hline Charlson co-morbidity index & $0.86(0.71-1.04)$ & 0.128 & $0.78(0.63-0.97)$ & 0.026 \\
\hline Days on chest tube before first bronchoscopy & $1.00(0.98-1.01)$ & 0.972 & $1.00(0.98-1.02)$ & 0.832 \\
\hline
\end{tabular}

Abbreviations: $\mathrm{Cl}=$ confidence interval; $\mathrm{EBV}=$ endobronchial valve; $\mathrm{HR}_{\mathrm{adj}}=$ adjusted hazard ratio; $\mathrm{HR}_{\mathrm{unadj}}=$ unadjusted hazard ratio

* Adjusted for 'days on chest tube before first bronchoscopy' and factors with $\mathrm{P}<0.2$ in univariable regression analyses

TABLE 3. Comparison between cases of success and failure*

\begin{tabular}{|c|c|c|c|c|c|}
\hline & \multicolumn{3}{|c|}{ EBV implanted } & \multirow{2}{*}{$\begin{array}{l}\text { All failures } \\
\qquad(n=29)\end{array}$} & \multirow[t]{2}{*}{$\mathbf{P}$ valuet } \\
\hline & Success $(n=8)$ & Failure $(n=11)$ & P value† & & \\
\hline Age, y & $71(59.0-77.5)$ & $73(65.0-84.0)$ & 0.545 & $71(65.0-79.0)$ & 0.814 \\
\hline Males, No. (\%) & $8(100)$ & $8(72.7)$ & 0.228 & $26(89.7)$ & $>0.999$ \\
\hline Ever-smokers, No. (\%)‡ & $2(66.7)$ & $7(77.8)$ & $>0.999$ & $17(85.0)$ & 0.453 \\
\hline Charlson co-morbidity index & $1(0.25-1)$ & $2(1-6)$ & 0.020 & $2(1-3)$ & 0.029 \\
\hline Left pneumothorax, No. (\%) & $2(25.0)$ & $5(45.5)$ & 0.633 & $13(44.8)$ & 0.431 \\
\hline Secondary pneumothorax, No. (\%) & $6(75.0)$ & $11(100)$ & 0.164 & $27(93.1)$ & 0.198 \\
\hline $\mathrm{FEV}_{1}, \mathrm{~L} \S$ & $0.71(0.67-0.78)$ & $0.99(0.54-1.72)$ & 0.548 & $1.03(0.85-1.51)$ & 0.031 \\
\hline $\mathrm{FEV}_{1} \%$ predicted§ & $30(26-40)$ & $43.0(30-84)$ & 0.310 & $45(34-61)$ & 0.071 \\
\hline $\mathrm{FEV}_{1} / \mathrm{FVC} \S$ & $0.34(0.31-0.47)$ & $0.67(0.36-0.69)$ & 0.095 & $0.49(0.36-0.68)$ & 0.058 \\
\hline Medical pleurodesis before bronchoscopy, No. (\%) & $3(37.5)$ & $3(27.3)$ & $>0.999$ & $8(27.6)$ & 0.672 \\
\hline Days on chest tube before first bronchoscopy & $36(17.5-48.0)$ & $25(23.0-49.0)$ & $>0.999$ & $24(16.0-31.0)$ & 0.236 \\
\hline No. of EBVs implanted & $3(2.25-3.75)$ & $2(1.00-3.00)$ & 0.177 & - & - \\
\hline Immediate air-leak cessation after EBV implantation, No. (\%) & $8(100)$ & $3(27.3)$ & 0.003 & - & - \\
\hline
\end{tabular}

Abbreviations: $\mathrm{EBV}=$ endobronchial valve; $F E V_{\text {, }}=$ forced expiratory volume in I second; FVC = forced vital capacity

* Values are expressed as median (interquartile range), except where noted; definition of success was air-leak cessation within 72 hours after implantation of the required number of EBVs

† Compared with success cases by Fisher's exact test or Mann-Whitney $U$ test, as appropriate

No. of cases: Success $=3$, Failure $=9$, All failures $=20$

$\S$ For patients with secondary pneumothorax only (No. of cases: Success $=5$, Failure $=5$, All failures $=17$ ) 
to screen for successful EBV treatment among the 23 patients who had undergone thoracic computed tomography, the accuracy was $69.6 \%$, the sensitivity and negative predictive value were both $100 \%$, and the specificity and positive predictive value were $58.8 \%$ and $46.2 \%$, respectively (Table 4 ). When the criterion for success was immediate air-leak cessation after EBV implantation, the accuracy among the 19 patients with an implanted EBV was $84.2 \%$, the sensitivity and negative predictive value remained at $100 \%$, and both the specificity and positive predictive value were $72.7 \%$ (Table 4 ).

\section{Adverse events and mortality}

There was no incident of valve displacement, bleeding, or post-obstructive pneumonia. Three patients died within 30 days of EBV implantation and all had advanced age and multiple co-morbidities (Table 5). In two patients, the causes of death were clearly related to ongoing pre-existing disease. One patient had a sudden cardiac arrest on day 29 after being successfully treated with EBV, although the relationship of death to EBV was uncertain. The earliest death in the no-EBV group occurred on day 43 after bronchoscopy and the cause of death was lung cancer.

\section{Subsequent treatments}

Three patients underwent a second bronchoscopy after the first one failed, with one success and two failures. Sixteen patients received talc pleurodesis (median, 2 times; range, 1-5 times). One young patient with primary spontaneous pneumothorax underwent surgery 2 days after failed identification of the leak site by bronchoscopy. Seventeen patients did not receive any further treatment, mostly owing to early air-leak cessation.

\section{Implant removal}

Thirteen patients had their implanted EBVs removed after a median of 43 days (range, 21-155 days). For the remaining six patients, three died within 30 days before EBV removal was considered. Another patient had a second bronchoscopy with an additional EBV implanted but died within 30 days of the second bronchoscopy. The fifth patient had advanced lung cancer and removal of EBV was deemed unnecessary; she died 9 months after bronchoscopy. The sixth patient had severe chronic obstructive pulmonary disease and there was subjective improvement of respiratory and health status after EBV implantation, so it was decided that the EBV should remain in situ indefinitely.

\section{Discussion}

We have reported the first real-life cohort study that consisted entirely of spontaneous pneumothorax cases with persistent air leak treated with EBV. Our results confirm those of previous reports that EBV can be useful in hastening air-leak cessation in patients with this condition. Nonetheless, it also highlights the fact that failures are common. A site for EBV implantation was not identified in nearly half of the patients. For the 19 patients with an EBV

TABLE 4. Prediction of successful outcome by fissure integrity and air-leak cessation after endobronchial valve implantation

\begin{tabular}{lcc}
\hline & All fissures intact & $\begin{array}{c}\text { Immediate and complete air-leak cessation } \\
\text { after EBV implantation† }\end{array}$ \\
\hline Accuracy $(95 \% \mathrm{Cl}), \%$ & $69.57(49.14-84.40)$ & $84.21(62.44-94.48)$ \\
Sensitivity $(95 \% \mathrm{Cl}), \%$ & $100(60.97-100)$ & $100(67.56-100)$ \\
Specificity $(95 \% \mathrm{Cl}), \%$ & $58.82(36.01-78.39)$ & $72.73(43.44-90.25)$ \\
Positive predictive value $(95 \% \mathrm{Cl}), \%$ & $46.15(23.21-70.86)$ & $72.73(43.44-90.25)$ \\
Negative predictive value $(95 \% \mathrm{Cl}), \%$ & $100(72.25-100)$ & $100(67.56-100)$ \\
\hline
\end{tabular}

Abbreviations: $\mathrm{Cl}=$ confidence interval; $\mathrm{EBV}=$ endobronchial valve

* No. of cases: Success=6, All failures $=17$

$\dagger$ No. of cases: Success=8; Failure with EBV implanted $=$ I I

TABLE 5. Characteristics of patients with endobronchial valve implantation who died within 30 days of bronchoscopy

\begin{tabular}{|c|c|c|c|c|c|c|c|}
\hline Sex & Age, y & Co-morbidities & $\begin{array}{c}\text { Charlson } \\
\text { co-morbidity } \\
\text { index }\end{array}$ & $\begin{array}{l}\text { Air-leak cessation } \\
\text { after bronchoscopy, } \\
\text { days }\end{array}$ & Outcome & $\begin{array}{c}\text { Survival after } \\
\text { bronchoscopy, } \\
\text { days }\end{array}$ & Terminal event \\
\hline Male & 79 & COPD, HT, DM, CHF, AF & 4 & 12 & Failure & 21 & Rapid AF, CHF \\
\hline Male & 87 & HT, DM, CHF & 3 & 0 & Success & 29 & Sudden cardiac arrest \\
\hline Male & 79 & Lung cancer, HT, DM & 8 & 11 & Failure & 29 & Lung cancer \\
\hline
\end{tabular}

Abbreviations: $\mathrm{AF}=$ atrial fibrillation; $\mathrm{CHF}=$ congestive heart failure; $\mathrm{COPD}=$ chronic obstructive pulmonary disease; $\mathrm{DM}=$ diabetes mellitus; $\mathrm{HT}=$ hypertension 
implanted, only eight (42\%) had a clear success. The overall success rate was thus only $22 \%$.

In this retrospective study, we attempted to assess the efficacy of EBV treatment by comparing those who had an EBV implanted with those in whom EBV implantation was denied owing to inability to identify an implantation site or lung function that was too poor. This design is obviously inferior to a prospective randomised design. Nevertheless, the two study groups had a similar number of patients who were similar in many demographic and disease aspects. The Kaplan-Meier comparison suggested that EBV treatment is efficacious in hastening airleak cessation. The significantly longer duration of air leakage before first bronchoscopy for the EBV group is a potential confounder, because the longer the air leak exists, the higher the probability that spontaneous resolution will occur. Nonetheless, the Cox hazards regression analysis suggested that it was not a significant factor. This finding also lends further support to the efficacy of EBV implantation in enabling early air-leak cessation.

A definition of success for using EBV implantation to treat persistent air leak complicating pneumothorax is difficult to formulate and has seldom been discussed in previous studies. Our criteria of cessation of air leak within 72 hours was arbitrary but is supported by our observation that patients who did not meet the criteria behaved almost exactly as if no EBV was implanted. This finding suggests that for cases in which EBV is implanted but fails, other forms of treatment should be sought early.

One interesting finding is that higher comorbidity burden seemed to be a risk factor for delayed air-leak cessation, irrespective of EBV implantation status. Delayed cessation of air leak may be translated as delayed healing of the lesion responsible for the air leak, which is expected in patients with more co-morbidities and who are thus usually sicker. Nonetheless, our study was not designed to examine this association, and a properly designed study would be needed to provide definitive answers.

It has been widely accepted that fissure completeness of the target lobe is strongly correlated with significant lobar collapse after implantation of EBVs for volume reduction in severe pulmonary emphysema. ${ }^{28,29}$ The same is probably true for EBV treatment of persistent air leak complicating pneumothorax, although as far as we are aware there are no published data on this. Not surprisingly, our results showed that intact interlobar fissures were a necessary, but not sufficient, condition for a successful outcome. However, an interesting and unexpected finding is that patients with a non-intact fissure in the contralateral lung, but intact fissure in the ipsilateral lung, behaved similarly to those with a non-intact fissure in the ipsilateral lung. We have no explanation for this, and these findings need to be confirmed with larger studies.

Immediate cessation of air leak after completion of EBV implantation was strongly predictive of a successful outcome. Importantly, all eight patients with an implanted EBV and without immediate cessation of air leak failed to respond to treatment. In such cases, the EBV should have been removed immediately to save costs and to avert possible adverse events associated with EBVs. A further implication is that stringent balloon testing of cessation of air leak should be performed and, in the presence of any uncertainty, EBVs should not be implanted.

In all our patients, we encountered no adverse events directly attributable to EBVs. Nonetheless, the three early deaths within 30 days of EBV implantation is worrying. The causes of death in two cases were clearly the severe pre-existing illness, but the possibility that recent EBV implantation hastened the terminal event cannot be excluded. The case of sudden cardiac death raises suspicion that the implanted EBV was implicated. More data are needed to determine whether EBV implantation is associated with increased early mortality.

There were several limitations to our study. First, it was a retrospective one, so some data were unavailable. Second, it was not a randomised controlled study. Third, it was a single-centre study, making the data less generalisable to a wider setting. Still, single-centre retrospective case series do have the advantage that practices are more uniform and results easier to interpret. Fourth, our case series was small, making it difficult to identify definitive factors associated with clinical outcomes. Fifth, some groups had a very small number of patients, and especially of females, patients with primary spontaneous pneumothorax, and patients with a lesion in the lower lobes. Finally, chart review and data collection (besides radiological data) were performed by an investigator who was not blinded to the study outcomes, and this may have been a source of bias.

We conclude that EBV implantation via the flexible bronchoscope can be useful in hastening air-leak cessation in patients with persistent air leak complicating spontaneous pneumothorax. Only about one-fifth of subjects, however, showed unequivocal benefit, and safety of this form of treatment needs further evaluation. Bilateral intact interlobar fissures seem to be a necessary, though not sufficient, condition for treatment success, and patients with fewer medical co-morbidities and immediate air-leak cessation after completion of EBV implantation seem to have a higher likelihood of treatment success. Further evaluation by randomised controlled trials is warranted. 


\section{Acknowledgements}

We thank the doctors and nurses of the Respiratory Team, Princess Margaret Hospital, for taking care of the patients, and nurses of the Central Endoscopy Unit, Princess Margaret Hospital, for providing technical support for the bronchoscopy procedures.

\section{Declaration}

The authors have no conflicts of interest to disclose.

\section{References}

1. Mathur R, Cullen J, Kinnear WJ, Johnston ID. Time course of resolution of persistent air leak in spontaneous pneumothorax. Respir Med 1995;89:129-32.

2. Chee CB, Abisheganaden J, Yeo JK, et al. Persistent airleak in spontaneous pneumothorax-clinical course and outcome. Respir Med 1998;92:757-61.

3. Snell G, Holsworth L, Fowler S, et al. Occlusion of a broncho-cutaneous fistula with endobronchial one-way valves. Ann Thorac Surg 2005;80:1930-2.

4. Ferguson JS, Sprenger K, Van Natta T. Closure of a bronchopleural fistula using bronchoscopic placement of an endobronchial valve designed for the treatment of emphysema. Chest 2006;129:479-81.

5. Mitchell KM, Boley TM, Hazelrigg SR. Endobronchial valves for treatment of bronchopleural fistula. Ann Thorac Surg 2006;81:1129-31.

6. Feller-Kopman D, Bechara R, Garland R, Ernst A, Ashiku S. Use of a removable endobronchial valve for the treatment of bronchopleural fistula. Chest 2006;130:273-5.

7. Fann JI, Berry GJ, Burdon TA. The use of endobronchial valve device to eliminate air leak. Respir Med 2006;100:1402-6.

8. Anile M, Venuta F, De Giacomo T, et al. Treatment of persistent air leakage with endobronchial one-way valves. J Thorac Cardiovasc Surg 2006;132:711-2.

9. Toma TP, Kon OM, Oldfield W, et al. Reduction of persistent air leak with endoscopic valve implants. Thorax 2007;62:830-3.

10. Santini M, Fiorelli A, Vicidomini G, Laperuta P, Di Crescenzo VG. Iatrogenic air leak successfully treated by bronchoscopic placement of unidirectional endobronchial valves. Ann Thorac Surg 2010;89:2007-10.

11. Yu WC, Yeung YC, Chang Y, et al. Use of endobronchial one-way valves reveals questions on etiology of spontaneous pneumothorax: report of three cases. J Cardiothorasc Surg 2009; 4:63.

12. Schiavon M, Marulli G, Zuin A, et al. Endobronchial valve for secondary pneumothorax in a severe emphysema patient. Thorac Cardiovasc Surg 2011;59:509-10.

13. El-Sameed Y, Waness A, Al Shamsi I, Mehta AC. Endobronchial valves in the management of bronchopleural and alveolo-pleural fistulae. Lung 2012;190:347-51.

14. Ambrosino N, Ribechini A, Allidi F, Gabbrielli L. Use of endobronchial valves in persistent air leaks: a case report and review of the literature. Expert Rev Respir Med 2013;7:85-90

15. Travaline JM, McKenna RJ Jr, De Giacomo T, et al. Treatment of persistent pulmonary air leaks using endobronchial valves. Chest 2009;136:355-60.

16. Gillespie CT, Sterman DH, Cerfolio RJ, et al. Endobronchial valve treatment for prolonged air leaks of the lung: a case series. Ann Thorac Surg 2011;91:270-3.

17. Mahajan AK, Verhoef P, Patel SB, Carr G, Kyle Hogarth D. Intrabronchial valves: a case series describing a minimally invasive approach to bronchopleural fistulas in medical intensive care unit patients. J Bronchol Intervent Pulmonol 2012;19:137-41.

18. Firlinger I, Stubenberger E, Müller MR, Burghuber OC, Valipour A. Endoscopic one-way valve implantation in patients with prolonged air leak and the use of digital air leak monitoring. Ann Thorac Surg 2013;95:1243-9.

19. Dooms CA, Decaluwe H, Yserbyt J, De Leyn P, Van Raemdonck D, Ninane V. Bronchial valve treatment for pulmonary air leak after anatomical lung resection for cancer. Eur Respir J 2014;43:1142-8.

20. Cordovilla R, Torracchi AM, Novoa N, et al. Endobronchial valves in the treatment of persistent air leak, an alternative to surgery [in English, Spanish]. Arch Bronconeumol 2015;51:10-5.

21. Reed MF, Gilbert CR, Taylor MD, Toth JW. Endobronchial valves for challenging air leaks. Ann Thorac Surg 2015;100:1181-6.

22. Hance JM, Martin JT, Mullett TW. Endobronchial valves in the treatment of persistent airleaks. Ann Thorac Surg 2015;100:1780-6.

23. Gilbert CR, Casal RF, Lee HJ, et al. Use of one-way intrabronchial valves in air leak management after tube thoracostomy drainage. Ann Thorac Surg 2016;101:1891-6.

24. Miller MR, Hankinson J, Bursasco V, et al. Standardisation of spirometry. Eur Respir J 2005;26:319-38.

25. Ip MS, Ko FW, Lau AC, et al. Updated spirometric reference values for adult Chinese in Hong Kong and implications on clinical utilization. Chest 2006;129:384-92.

26. Sciurba FC, Ernst A, Herth FJ, et al. A randomized study of endobronchial valves for advanced emphysema. N Engl J Med 2010;363:1233-44.

27. von Elm E, Altman DG, Egger M, Pocock SJ, Gøtzsche PC, Vandenbroucke JP; STROBE Initiative. The Strengthening the Reporting of Observational Studies in Epidemiology (STROBE) statement: guidelines for reporting observational studies. J Clin Epidemiol 2008;61:344-9.

28. Koster TD, van Rikxoort EM, Huebner RH, et al. Predicting lung volume reduction after endobronchial valve therapy is maximized using a combination of diagnostic tools. Respiration 2016;92:150-7.

29. Schuhmann M, Raffy P, Yin Y, et al. Computed tomography predictors of response to endobronchial valve lung reduction treatment. Comparison with Chartis. Am J Respir Crit Care Med 2015;191:767-74. 